\title{
O PROCESSO DE ALFABETIZAÇÃO ÉTNICO-CULTURAL EM CARTILHAS TEUTO-BRASILEIRAS PRODUZIDAS PARA ESCOLAS SINODAIS
}

\author{
Elias Kruger Albrecht ${ }^{*}$ \\ Lisiane Sias Manke**
}

\section{RESUMO}

O estudo tem por objetivo analisar um conjunto de recursos textuais e visuais presentes em duas cartilhas utilizadas em escolas teuto-brasileiras, de modo a compreender como tais recursos contribuíram para o que se convencionou denominar como alfabetização étnico-cultural dos sujeitos a que se destinavam. A análise documental possibilitou concluir que o conteúdo das cartilhas contemplava o contexto rural e as práticas socioculturais dos estudantes, como modo de interlocução com os mesmos.

Palavras-chave: cartilhas teuto-brasileiras, alfabetização, recursos textuais e visuais.

\footnotetext{
${ }^{*}$ Universidade Federal de Pelotas (UFPel), Pelotas/RS, Brasil.

${ }^{* *}$ Universidade Federal de Pelotas (UFPel), Pelotas/RS, Brasil.
} 


\section{EL PROCESO DE ALFABETIZACIÓN ÉTNICO-CULTURAL EN FOLLETOS GERMANO-BRASILEÑOS PRODUCIDOS PARA ESCUELAS SINODALES.}

\section{RESUMEN}

El estudio tiene como objetivo analizar un conjunto de recursos textuales y visuales presentes en dos folletos utilizados en las escuelas germano-brasileñas, con el fin de comprender cómo estos recursos contribuyeron a lo que se llamó, convencionalmente, la alfabetización étnico-cultural de los sujetos a los que estaban destinados. El análisis documental permitió concluir que los contenidos de los folletos contemplaban el contexto rural y las prácticas socioculturales de los estudiantes, como una forma de dialogar con ellos.

Palabras clave: cartillas germano-brasileños, literatura, recursos textuales y visuales.

\section{THE ETHNICAL-CULTURAL LITERACY PROCESS IN GERMAN-BRAZILIAN BOOKLETS PRODUCED AT SYNODAL SCHOOLS}

\section{ABSTRACT}

The study is aimed at analyzing a range of textual and visual resources found in two booklets used at German-Brazilian schools in order to understand how such resources contributed for what is so-called ethnical-cultural literacy of the subjects it was aimed at. The document analysis enabled concluding that the content of the booklets considered the rural setting and the sociocultural practices of the students, as a way of communication with them.

Keywords: german-Brazilian booklets, literacy, textual and visual resources.

\section{LE PROCESSUS D'ALPHABETISATION ETHNOCULTURELLE DANS DES LIVRES SCOLAIRES GERMANO-BRESILIENS PRODUITS POUR LES ECOLES SYNODALES}

\section{RESUME}

Cet étude a pour but d'analyser un ensemble de ressources textuelles et visuelles trouvées dans deux livres utilisés dans des écoles germano-brésiliennes, afin de comprendre comment ces ressources ont contribué pour ce que l'on a appelé conventionellement alphabétisation ethnoculturelle des sujets auxquels ces livres étaient destinés. L'analyse de documents a mené à la conclusion que le contenu des livres adressait le contexte rural et les pratiques socioculturelles des étudiants, comme moyen d'interlocution avec eux.

Mots-clés: livres scolaires germano-brésiliens, alphabétisation, ressources textuelles et visuelles. 


\section{INTRODUÇÃO}

Neste artigo temos por objetivo analisar um conjunto de recursos textuais e visuais que compõem o conteúdo das cartilhas Schreiblesefibel für Unterricht der Elementarklassen ${ }^{1}$, produzida pela editora Concórdia² e Fibel für Deutsche Schulen in Brasilien3, da editora Rotermund4, de modo a compreender a forma como tais recursos foram mobilizados para o que se convencionou denominar como alfabetização étnico-cultural dos sujeitos a que se destinavam. As cartilhas, produzidas na década de 1920, eram utilizadas em escolas teuto-brasileiras, ligadas aos sínodos luteranos, que administravam, além das escolas, também as editoras produtoras desses livros escolares. Como tratava-se de uma produção para atender as demandas de um público específico, os teuto-brasileiros adeptos ao luteranismo, essas cartilhas eram elaboradas levando em consideração os princípios doutrinários e ideológicos defendidos pelos sínodos luteranos (DREHER, 1984; WEIDUSCHADT, 2007), bem como o contexto rural e as práticas socioculturais dos estudantes para os quais se destinavam (KREUTZ, 1994, 19995). Portanto, esses materiais didáticos estavam vinculados a um projeto comunitário sob a liderança das igrejas, que visava, tanto o aspecto social e religioso, quanto às formas de organizar as relações de trabalho.

Com base nas orientações teóricas de autores como Kreutz (1994), Arendt (2005), Weiduschadt (2007), Weiduschadt e Tambara (2016) ${ }^{6}$, havia um

\footnotetext{
${ }^{1}$ Cartilha de Leitura e escrita para o ensino da educação básica (tradução do autor).

2 Editora fundada no Brasil em 1923, em Porto Alegre, como Sociedade Tipográfica por Ações, por um grupo de professores, de pastores e de leigos e, por conseguinte, ligada ao Sínodo de Missouri, atual Igreja Evangélica Luterana do Brasil (IELB). Para saber mais sobre ver Weiduschadt (2007) e Albrecht (2019).

3 Cartilha para as escolas alemãs no Brasil (tradução do autor).

4 Editora fundada em 1877, em São Leopoldo/RS, pelo Pastor Dr. Wilhelm Rotermund (18431925) e ligada ao Sínodo Rio-Grandense, atual Igreja Evangélica de Confissão Luterana no Brasil. Para saber mais sobre ver Dreher (2014) e Albrecht (2019).

5 Segundo kreutz (1999), a literatura teuto-brasileira, isso inclui livros e cartilhas escolares reivindicavam a manutenção de especificidades étnico culturais, porém, reconheciam e afirmavam a cidadania brasileira.

${ }^{6}$ Weiduschadt e Tambara (2016), fazem uma análise comparativa das diferenças e aproximações de cartilhas e livros escolares produzidos pelos Sínodos Luteranos Missouri e Rio-grandense, que circularam entre as comunidades pomeranas na região de Canguçu, Pelotas e São Lourenço
} 
incentivo para que o processo pedagógico de ensino e aprendizagem, bem como a produção do material didático, partisse sempre da realidade do aluno. O que nos leva a problematizar o quanto esse aspecto esteve relacionado as estratégias de manutenção da cultural teuto-brasileira, por intermédio da escolarização e adoção de recursos visuais em suportes didáticos, que valorizassem e incentivassem os modos de ser e viver em comunidade7, o que estamos denominando neste texto como alfabetização étnico-cultural. De modo que, é possível compreender que as ilustrações presentes nas cartilhas analisadas serviam como instrumento de aproximação, valorização e manutenção das práticas socioculturais das comunidades a que se destinavam, tendo por finalidade última a representação de palavras com vistas a alfabetização na língua alemã.

A utilização de ilustrações para o ensino da leitura e da escrita era algo presente nas propostas educacionais, especialmente no final do século XIX e no início do XX. A título de exemplo, é possível considerar o manual Lição de Coisas, que se utilizava de imagens para o ensino das crianças, obra didática bastante difundida no período (VALDEMARIN, 2010). Assim, com base nas leituras de Valdemarin (2000), compreendemos que a proposta de ensino dessas cartilhas, apesar de apresentarem diferenças significativas na organização ilustrativa, estão fundamentadas no método de ensino intuitivo ou lições das coisas, que tem na operação dos sentidos o principal instrumento da aprendizagem. Constatações que são reforçadas por Kreutz (1994), ao afirmar que o conteúdo das cartilhas teuto-brasileiras predominava pedagogicamente o método da Realia ${ }^{8}$, ou seja, o ensino a partir da realidade do aluno.

Para Chartier (2001), a organização textual, como a disposição e divisão

do Sul.

7 O termo comunidade aqui é empregado sociologicamente para se referir a pessoas que se organizam sob o mesmo conjunto de normas, geralmente vivem no mesmo local, e compartilham o mesmo legado cultural e histórico. Ver Mocellim (2011).

$8 \mathrm{O}$ realismo pedagógico apresentou um ensino prático, útil e voltado para a realidade, mantendo a atenção concentrada na observação do meio no caso da realidade das escolas rurais teutas instrumentos do trabalho rural, retrato da vida doméstica e mercado local. Para saber mais sobre ver: Hoff e Cardoso (2006). 
do texto, sua tipografia, sua ilustração, aproximam e direcionam o leitor a uma maneira de ler o texto. Além disso, a linguagem visual nas cartilhas direcionados à alfabetização servem como alicerce para chegar à escrita (BELMIRO, 2008). Nelas a ilustração assume um papel pedagógico de aproximar o conhecimento visual da criança com a motivação do significado alfabético.

Desta maneira os caminhos metodológicos adotados para este estudo pautaram-se nos princípios da investigação da análise documental, conforme Bacellar (2008), que consiste na realização de um estudo contextualizado, baseado na interpretação coerente dos documentos, que são os testemunhos históricos, "[...] resultado de uma montagem, consciente ou inconsciente, da história, da época, da sociedade que os produziu e também das épocas sucessivas durante as quais continuaram a existir (LE GOFF, 1996, p. 538)". Nessa perspectiva Choppin (2002), afirma que os manuais escolares são fontes de pesquisa por excelência, pois, enquanto instrumentos de ensino e formadores de mentalidades influenciam a formação de identidades em contextos e épocas distintas.

E como produto de um contexto histórico, social, político e religioso, sofrem ações do governo, influência da igreja e da própria sociedade civil, necessitando assim, de uma problematização contextualizada com o período da sua produção (CHOPPIN, 2002). Outrossim, Batista e Galvão (2009) reforçam que o manual escolar é a expressão do que a sociedade considera importante ensinar em determinadas épocas ou culturas, auxiliando assim a compreender comportamentos sociais específicos. Uma vez que "[...] reproduzem e condicionam um modo de organização da cultura escolar, concepções pedagógicas e maneiras de escolarizar saberes," (BATISTA; GALVÃO, 2009, p. 16).

Assim, pesquisar em cartilhas escolares é algo complexo e ao mesmo tempo desafiador, pois são produtos de uma época e constituíram diferentes suportes e contemplaram diferentes interesses. Mas essas particularidades fazem desses materiais um objeto privilegiado para compreender as mentalidades de 
uma época.

Após o exercício de apresentação dos referenciais teóricos que norteiam este estudo, torna-se pertinente perseguir os objetivos específicos da análise, de modo a compreender a forma de apresentação e organização das cartilhas, bem como os protocolos de leitura deixados pelo autor e/ou editor. Uma vez que, como bem indica Chartier (2001), esses arranjos e procedimentos de uso aproximam ou direcionam o leitor à uma maneira de ler. Por fim, analisamos como os autores e editores das cartilhas se apropriaram de recursos visuais relacionados ao cotidiano das comunidades teuto-brasileiras para contemplar um processo de alfabetização étnico-cultural e intuitivo.

\section{ORGANIZAÇÃO E APRESENTAÇÃO: PRIMEIRAS APROXIMAÇÕES COM A MATERIALIDADE DAS CARTILHAS}

Inicialmente, antes de abordar o conteúdo das cartilhas e refletir sobre a proposta de ensino-aprendizagem por intermédio das representações ilustrativas, realizaremos um exercício de olhar a materialidade das cartilhas, por considerarmos pertinente a análise do conteúdo sempre associada a materialidade do suporte escrito. Uma vez que, assim como o conteúdo e a proposta de ensino são produtos de um período específico, a materialidade dos livros também o são, ou seja, a estrutura física bem como o modo de organização das cartilhas são resultado de determinado período histórico.

Desta maneira Chartier (1990) e Frade (2010), chamam a atenção para importância de observar a materialidade e os protocolos de leitura, pois o modo de organização e apresentação das cartilhas possibilitará conhecer os códigos culturais estabelecidos, bem como aproximar-se das propostas de uso destes manuais escolares, visto que são indicadores que buscam aproximar o leitor do objeto de leitura. Assim é conveniente, antes de dar seguimento na análise dos 
conteúdos, projetar o olhar sobre a estrutura física das cartilhas, visto que elas podem tanto ser tomadas como um documento impresso, quanto como um produto cultural.

Figura 1 - Capa da Fibel.

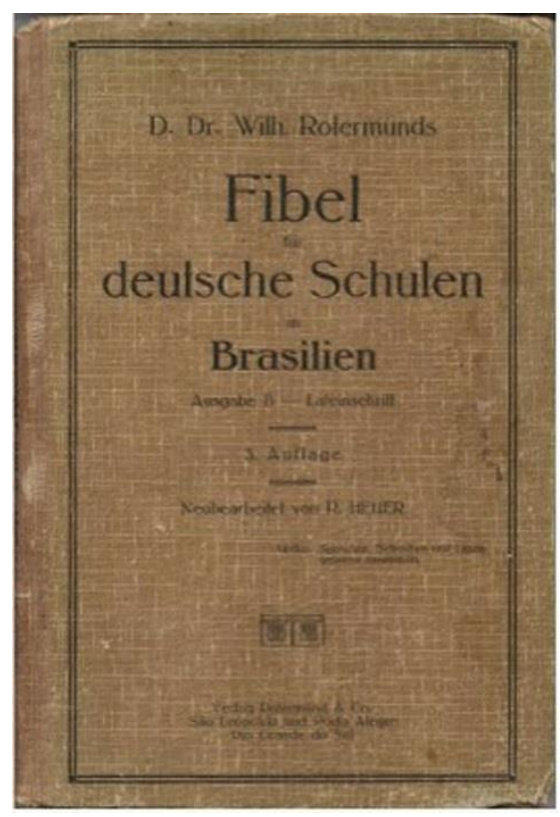

Fonte: Acervo do Hisales

A Fibel für Deutsche Schulen in Brasilien, (Figura 1) que integra o presente estudo foi impressa no ano de 1927, e é fruto de sucessivas edições e reedições entre 1878 quando foi produzida pela primeira vez por Wilhelm Rotermund9 (1843-1925) até 1932, sofrendo ao longo do tempo reelaborações ${ }^{10}$,

\footnotetext{
9 Formado em Teologia pelas Universidades de Erlangen, no Reino da Baviera e Göttingen, em Hannover, atual Alemanha, Wilhelm Rotermund foi pastor luterano, professor, jornalista e autor de obras didáticas. Veio ao Brasil em 1874 para trabalhar como pastor. No ano de 1877 fundou a editora Rotermund, em 1878 laçou a primeira cartilha de sua autoria a Fibel für deutsche Schulen in Brasilien e em 1886 fundou o Sínodo Rio-Grandense.

${ }^{10}$ Localizamos em acervos particulares e em acervos públicos como o CEDOC - Centro de Documentação e o HISALES - História da Alfabetização, Leitura, Escrita e dos Livros Escolares, ambos ligados a FAE/UFPEL um total de 11 cartilhas Fibel, destas, 6 são em escrita gótica e 5, em escrita latina. Todas foram produzidas na década de 1920. As mesmas possuem características de apresentação e organização dos conteúdos semelhantes, porém algumas trazem o conteúdo do primeiro e segundo ano escolar separada e outras acopladas em uma única cartilha.
} 
modificações e acréscimos. A versão analisada foi assinada por Reinhard Heuer ${ }^{11}$ que passou a assinar a cartilha a partir de $1924 \mathrm{em}$ duas versões, edição A, (Ausgabe A - Deutsche Schrift) escrita em língua alemã, com a letra gótica, e a edição B (Ausgabe B - Lateinschrift) escrita em português. As edições anteriores a 1924 possuem somente a versão alemã.

Quanto à materialidade, trata-se de um manual didático que apresenta conforme Cardoso (2005), características comuns à maioria das cartilhas e livros produzidos na década de 1920: capa dura estilo brochura, folhas semelhantes ao papel jornal, transparecendo levemente as fibras e impressão preto e branco, possui um total de 186 páginas, além de ser amplamente ilustrada, reproduzindo situações do cotidiano ou da realidade e da cultura das comunidades teutobrasileiras. E suas dimensões aproximam 21 centímetros de altura por 14 centímetros de largura e 1,5 de espessura.

Com base em Chartier (1990), a descrição do corpo da cartilha em conjunto com a análise dos protocolos de leitura possibilita ao historiador conhecer os direcionamentos de uso deixados pelo autor, bem como as propostas educacionais e os códigos culturais estabelecidos. Observa-se que a Fibel ${ }^{12}$, é a terceira edição, B de escrita portuguesa e traz em anexo uma nota assinada por Reinhard Heuer, justificando a necessidade de adotar a escrita latina na Fibel com o objetivo de reforçar as habilidades das crianças em se adaptar com as duas formas de escrita, estimulando assim os seus sentidos. Ressalta também a questão da comunicação escrita, para facilitar a interlocução nos países latinos. Porém, o autor defende a manutenção da caligrafia alemã, por ser muito bem lida e compreendida nos países da Europa, onde o entendimento da caligrafia latina é superficial. A nota do autor deixa a entender que a elaboração da cartilha em duas versões de escrita foi motivada por um descontentamento e uma

\footnotetext{
${ }^{11}$ No período em que R. Heuer assumiu a autoria da Fibel, ele era também diretor do Deutsche Schule Collegio Allemão de Pelotas, cargo que ocupou de 1916 e 1926. Para saber mais sobre ver: Fonseca (2017).

12 Para facilitar a escrita, optou-se em usar apenas o primeiro nome da cartilha Fibel für Deutsche Schulen in Brasilien. E tendo em vista que Fibel em alemão significa cartilha, optou-se em manter somente "Fibel".
} 
obrigatoriedade. Por um lado, havia a crítica ao governo brasileiro por não levar a educação ao campo e propiciar com que o jovem teuto-brasileiro tivesse contato com a escrita local para facilitar a sua inserção no meio social brasileiro. E por outro, havia a mobilização do governo no sentido de proibir a escrita e a fala alemã.

Como se trata de uma cartilha de alfabetização e iniciação a leitura, dividida em primeiro e segundo ano escolar. No prefácio o autor chama a atenção do professor para o uso das ilustrações da cartilha por oferecer um rico material para uma aula visual. Esclarece que as figuras expostas nas respectivas páginas têm relação com as letras ensinada, assim para um melhor ensinamento seria mais proveitoso que o professor mostrasse as ilustrações da cartilha e utilizasse os suportes de leitura para estimular exercícios de fala nas quais a criança deveria descrever de forma oral o conteúdo visualizado e desenvolvessem frases e pequenos textos relacionados, o que iria capacitar o ensino da escrita e da leitura. $\mathrm{O}$ autor reforça assim, as vantagens do uso dos recursos visuais com ênfase na ilustração, que, segundo Belmiro (2008), nos livros didáticos direcionados à alfabetização servem como alicerce para chegar à escrita, auxiliando ainda exercícios de fala, soletração e memorização.

A outra cartilha analisada é a Schreiblesefibel für Unterricht der Elementarklassen (Figura 2) produzida pela editora Concórdia, não traz a informação do ano da impressão, porém como o sínodo fundou a sua editora no Brasil no ano de 1923, sua impressão data, provavelmente, na segunda metade da década de 1920. O mesmo acontece em relação ao editor e ilustrador, sendo que tais informações não foram encontradas durante o período pesquisado. A ausência do ano de produção é recorrente em outras cartilhas do sínodo, inclusive nas que foram produzidas na Concordia Publishing House nos Estados Unidos e circularam aqui antes da fundação da editora Concórdia no Brasil. 
Figura 2 - Capa da Schreiblesefibel.

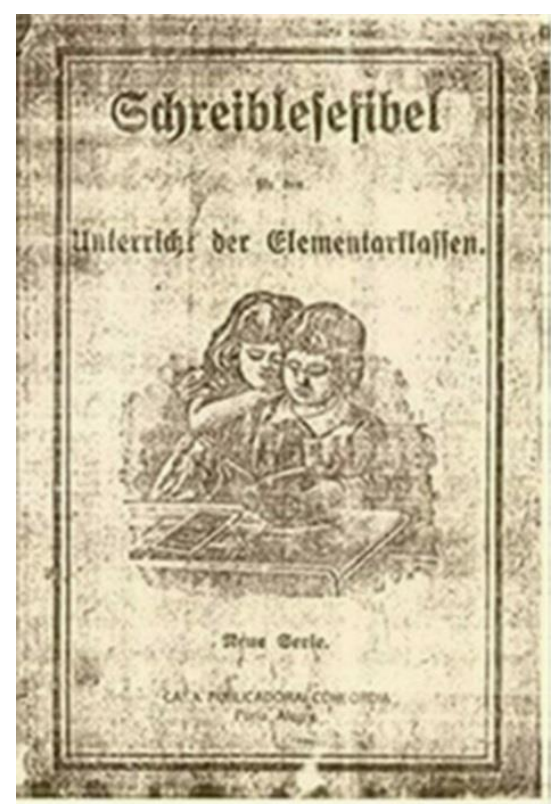

Fonte: Arquivo particular.

Quanto a sua materialidade a Schreiblesefibel 13 é do tipo brochura, as folhas são presas entre si por uma costura e cola, e unidas por uma faixa de papel mais mole, que as fixa ao material da capa, possui um total de 62 páginas, sendo que em 46 delas encontram-se ilustrações referentes a cotidiano e a cultura das comunidades teuto-brasileiras. E possui 20 centímetros de altura, com 13 centímetros de largura e aproximadamente 1 centímetro de espessura na lombada. A obra traz na capa uma apresentação visual, com a ilustração de duas crianças, uma sentada à mesa e a outra escorada em seu ombro dividindo o mesmo livro. O que segundo Cardoso (2005) tratava-se de uma técnica ainda pouco usada no Brasil naquele período, visto que o mais comum era a reprodução em papel cinza e amarelo, dos caracteres tipográficos que apareciam na página de rosto.

Infelizmente um dos problemas mais recorrentes enfrentados por pesquisadores que estudam manuais escolares são as lacunas provocadas pela

${ }_{13}$ De maneira semelhante a Fibel, será usado somente o primeiro nome Schreiblesefibel für Unterricht der Elementarklassen. 
ação do tempo. Como folhas soltas, rasgadas, rabiscadas e ainda a falta de algumas páginas que se perdem com o desgaste do tempo. Porém segundo Frade (2004), isto não impede a sua análise, tendo em vista que a estrutura organizacional da cartilha pode oferecer informações sobre os usos e práticas culturais nelas representados.

As ponderações supracitadas são também algumas das dificuldades observadas em relação a Schreiblesefibel (Figura 2) visto que, falta-lhe o prefácio, o sumário e algumas páginas com atividades, com isso não é possível saber os direcionamentos de uso deixados pelo autor. Todavia a falta dos direcionamentos de uso da cartilha, não impediram de observar a importância dada à questão da apresentação e organização dos recursos didáticos. Essas configurações contribuíram para a compreensão dos usos dos recursos visuais operados na cartilha, possibilitando verificar a influência destes no processo de ensino e aprendizagem. Assim, quando se trata de uma cartilha, tão importante quanto o prefácio e o texto são os "indicadores puramente formais ou materiais: por exemplo, o formato e a imagem" (CHARTIER, 1990, p. 132). Sendo que estes apontam ao leitor qual o pré-saber, ou seja, como o assunto é visualmente apresentado.

\section{A METODOLOGIA DA ALFABETIZAÇÃO VISUAL CONTEXTUALIZADA}

Ao percorrer as cartilhas selecionados para a presente pesquisa, observase métodos e técnicas de ensino que foram elaboradas no sentido de servir como instrumento facilitador para instrumentalizar as crianças na leitura e na escrita. É com essa perspectiva que Frade (2010), afirma que os recursos gráficos, bem como os diferentes modos de apresentação e organização dos conteúdos textuais e visuais nos manuais didáticos não podem ser vinculados apenas a um método de ensino, visto que há um peso cultural na utilização destes recursos que podem variar de uma cultura para outra. Essas ponderações podem ser percebidas nas 
cartilhas analisadas, que apresentam peculiaridades metodológicas de ensino e aprendizagem. Nelas o recurso visual, além de um facilitador no processo de alfabetização visava uma formação contextualizada pela realidade vivenciada pelo aluno.

A Fibel tinha como metodologia reproduzir ilustrações do contexto onde o seu público alvo está inserido, com o objetivo estabelecer uma relação direta do público leitor como o espaço por ele habitado. Segundo Joly (2006) é justamente esse o papel da linguagem visual, fazer com que o homem se perceba e se relacione com o mundo em sua volta. Conforme pode ser observado na Figura 3, que apresenta uma atividade de alfabetização da Fibel, com um arranjo visual articulado com o ensino do encontro consonantal "sch". A representação ilustrativa evidencia que Fibel era pensada e organizada para que a criança aprendesse associando a letra a um objeto do seu cotidiano familiar ou a alguma espécie da fauna e da flora presente no seu espaço de vivência, que seriam facilmente reconhecidos na natureza.

Figura 3 - o ensino do SCH.

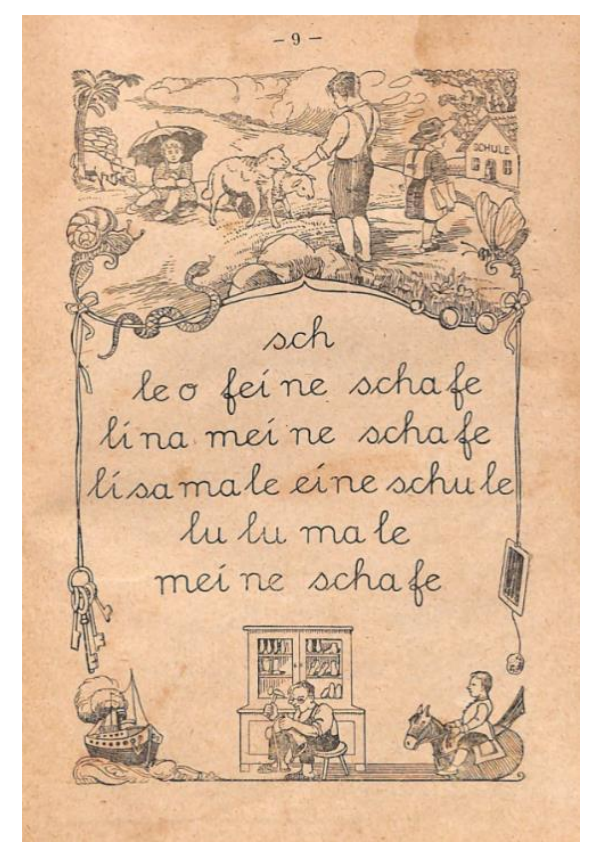

Fonte: Fibel, p. 9. 
Para demostrar a intencionalidade dos organizadores da Fibel em criar uma composição ilustrativa que dialogasse com o contexto e com a letra ensinada, entendemos conveniente realizar a transcrição para a forma gramatical de algumas ilustrações observadas na Figura $3^{14}$. Desta maneira faz-se notar a relação direta entre a ilustração e a letra ensinada, o que irá permitir um melhor entendimento da proposta de ensino da cartilha com o suporte da linguagem visual.

Quadro 1 - Transcrição ${ }^{15}$ para a língua alemã e portuguesa de ilustrações da figura 3.

\begin{tabular}{|c|c|c|}
\hline $\begin{array}{c}\text { ORTOGRAFIA } \\
\text { ALEMÃ }\end{array}$ & & $\begin{array}{c}\text { ORTOGRAFIA } \\
\text { PORTUGUESA }\end{array}$ \\
\hline Schafe & $=$ & Ovelha \\
\hline Schule & $=$ & Escola \\
\hline Schlange & $=$ & Serpente \\
\hline Schleife & $=$ & Laço \\
\hline Schiff & $=$ & Navio \\
\hline Schaftstiefel & $=$ & Bota \\
\hline Schrank & $=$ & Armário \\
\hline Schmetterling & $=$ & Borboleta \\
\hline Schuhmacher & $=$ & Sapateiro \\
\hline Schlüssel & $=$ & Chave \\
\hline Schaukeln & $=$ & Balanço \\
\hline Schwarzesbrett & $=$ & Quadro de escrever \\
\hline Schnecke & $=$ & Caramujo \\
\hline Schlagen & $=$ & Pregar \\
\hline Schirm ${ }^{16}$ & $=$ & Guarda-Chuva \\
\hline
\end{tabular}

Fonte: Quadro elaborado pelo autor a partir da observação de ilustrações na Figura 3.

Ao relacionar o quadro das transcrições com as ilustrações da figura 3 é perceptível o método de ensino que se utiliza da linguagem visual, estabelecendo

\footnotetext{
14 Como tratava-se de uma cartilha direcionada para atender as comunidades teuto-brasileiras, toda a metodologia está pensada para o ensino em língua alemã. Assim, optamos pela transcrição para ortografia portuguesa e alemã de nomes de alguns animais e objetos ilustrados na figura 3, que condiz a uma atividade de alfabetização da Fibel.

15 Tradução e interpretação feita pelo autor.

${ }^{16}$ Schirm é a expressão geral de uso, que serve tanto para guarda-chuva (Regenschirm) como para Sombrinha (Sonnenschirm).
} 
relação entre a letra ensinada e as representações ilustrativas do contexto diário do aluno, possibilitando a criança aprender por intermédio da ilustração. Uma vez que, todas as imagens que contornam o texto escrito possuem SCH na escrita. A mesma observação pode ser feita em relação ao ensino das demais letras do alfabeto e suas ramificações fonéticas, silabarias e encontros consonantais, como é o caso acima apresentado.

Conforme mencionado, a relação entre texto imagético e texto escrito é constante no decorrer da Fibel, sendo a ilustração uma extensão do texto escrito, ou mesmo, um complemento dele. Joly (2006), aponta que a mensagem visual tem como objetivo estabelecer uma relação entre o homem e o mundo. Assim, ao estabelecer essa relação verifica-se que toda a representação ilustrativa foi pensada para que a criança se veja num espaço familiar, no caso o ambiente rural, e aprenda por intermédio das ilustrações presentes na cartilha a assimilar as letras ensinadas, associando-as a esse contexto.

As crianças são colocadas como protagonistas na maioria dos textos e ilustrações presentes na Fibel, o que trata-se de um dispositivo textual que objetiva aproximar o texto do leitor visado. Para tanto, além do contorno ilustrativo que está dialogando com a letra ensinada, há também na parte superior de cada página uma pequena historinha ilustrada que dialoga com o texto escrito, de acordo com a tradução da Figura 3.

Quadro 2 - Tradução do texto escrito da Figura 3.

\begin{tabular}{|l|l|l|}
\hline \multicolumn{1}{|c|}{ ORTOGRAFIA ALEMÃ } & & \multicolumn{1}{c|}{ ORTOGRAFIA PORTUGUESA } \\
\hline Leo feine schafe & $=$ & Mimosas ovelhas do Leo! \\
\hline Lina meine schafe & $=$ & Lina, minhas ovelhas. \\
\hline Lisa male eine schule & $=$ & Lisa, desenha uma escola. \\
\hline Lulu, mal meine schafe & $=$ & Lulu, desenhe minhas ovelhas. \\
\hline
\end{tabular}

Fonte: Quadro elaborado pelos autores.

A pequena historieta descreve os acontecimentos ilustrados na parte superior da página, que apresenta três crianças em total harmonia com o meio 
sociocultural em que estão inseridas. Assim, ao relacionar o texto escrito e a forma como as crianças estão expostas nas ilustrações, podemos inferir uma ação e uma reação, ou seja, antes mesmo da criança ler já conseguia compreender a história representada, fazendo uma interpretação visual contextualizada com as suas experiências vivenciadas no cotidiano. Para Pesavento (2005), a representação construída sobre o mundo se coloca como mediadora, fazendo com que o homem perceba a realidade e pautem a sua existência em torno de atributos, características e valores socializados.

O contexto rural encontra-se amplamente difundido nas páginas da cartilha, sendo que a grande maioria das ilustrações faz referência a atividades típicas do homem que trabalha no campo. E no conjunto as ilustrações mostram a relação do homem com a natureza, o trabalho, a fé, o saber e o lazer. Neste seguimento, Chartier (1999), afirma que a leitura é sempre uma apropriação, invenção, e produção de significados, ou seja, de algum modo o leitor irá se apropriar da narrativa do texto e da ilustração e ressignificar socialmente a sua leitura. No caso das cartilhas em análise, observamos que, por trás de cada ilustração há uma narrativa de uma pequena história que foi pensada a partir da realidade da criança para contextualizar o ensino de uma determinada letra e seu uso gramatical. Sobretudo, o texto visual procura ressaltar os valores e costumes difundidos nas comunidades rurais alemãs e pomeranas ${ }^{17}$, teatralizando o que é considerado importante para viver bem em comunidade.

Havia assim, a intencionalidade do conteúdo da Fibel de estar relacionado a vivência da criança para formar nela uma consciência social sobre o meio no qual estava inserida, objetivando reforçar os aspectos socioculturais das comunidades teuto-brasileiras. Processo este, que denominamos como alfabetização étnico-cultural, ou seja, procedimentos educacionais que visavam,

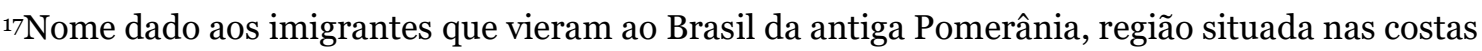
do mar Báltico, território atualmente incorporado pela Alemanha e Polônia. Hoje a sua cultura praticamente está extinta naquela região, mantendo-se viva entre algumas comunidades no Brasil que ainda preservam a língua e algumas práticas culturais e religiosas. Ver: Schaffer (2012). A cultura pomerana foi, muitas vezes, silenciada em detrimento da cultura alemã. Para saber mais do silenciamento dos pomeranos ver: Thum, (2009).
} 
a partir do uso de dispositivos textuais e visuais, desenvolver, além do ensino da leitura e da escrita, a plena inserção da criança ao seu meio sociocultural, preparando-a para integrar e cooperar com o desenvolvimento da comunidade.

Nesse sentido, considerando que o livro didático é usado historicamente para conservar e justificar aportes ideológicos. A cartilha Fibel foi pedagogicamente pensada para compreensão de práticas sociais do contexto para o qual foi produzida, procurando inculcar uma consciência a respeito do que era considerado importante para uma determinada sociedade. Outro exemplo de tais constatações podem ser observado na Figura 4, que traz um homem espalhando sementes na terra.

Figura 4 - o ensino da letra S.

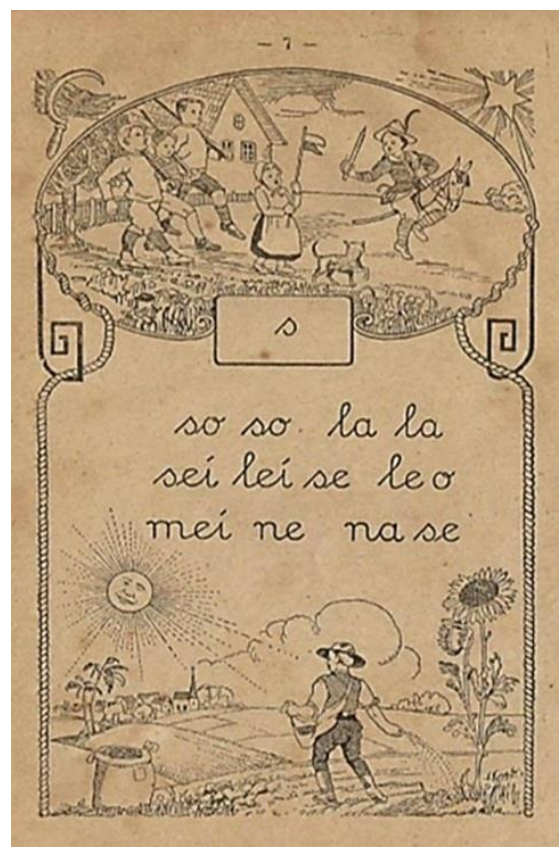

Fonte: Fibel, p. 7.

No caso dessa atividade percebe-se que todo o contexto da ilustração foi pensado e elaborado para contemplar o ensino da letra S. Além disso, as imagens usadas se adequam perfeitamente ao contexto de vivência diária das crianças. $\mathrm{Na}$ parte superior tem-se crianças brincando de soldado, ou soldad em alemão, ao pé 
da página tem-se a ilustração do campo onde um agricultor semeia a lavoura, säen em alemão. Contemplando assim, representações ilustrativas de atividades significativas para as comunidades alemães e pomeranas, como: a religiosidade (com a imagem da igreja no horizonte); o lazer (que é representada pelas crianças brincando fantasiadas de soldados, com cavalo e armas de brinquedo); e o trabalho na terra, lugar de onde tiravam o sustento.

Para além do que é exposto, as duas situações ilustradas contemplam imagens que são escritas com a letra $S$, conforme mostra a descrição em português e alemão das imagens da Figura 4.

Quadro 3 - Transcrição para a língua alemã e portuguesa das ilustrações da Figura 4.

\begin{tabular}{|l|l|l|}
\hline \multicolumn{1}{|c|}{$\begin{array}{c}\text { ORTOGRAFIA } \\
\text { ALEMÃ }\end{array}$} & \multicolumn{1}{c|}{$\begin{array}{c}\text { ORTOGRAFIA } \\
\text { PORTUGUESA }\end{array}$} \\
\hline Soldad & $=$ & Soldado \\
\hline säen & $=$ & Semear \\
\hline Samen & $=$ & Semente \\
\hline Sack & $=$ & Saco \\
\hline Sonnenblume & $=$ & Girassol \\
\hline Sonne & $=$ & Sol \\
\hline Seil & $=$ & Corda \\
\hline Sichel & $=$ & Foice \\
\hline Stern & $=$ & Stern \\
\hline
\end{tabular}

Fonte: Quadro elaborado pelos autores a partir da observação de ilustrações na Figura 4.

Outra metodologia recorrente na Fibel é a repetição de ilustrações utilizadas na apresentação do alfabeto em outras atividades relacionadas com a letra em questão (Figuras 5 e 6). Como se estivesse ocorrendo um exercício de recordar a lição a partir da imagem, ao apresentar para o aluno pequenos textos, com forma diferente de escrita, passando do uso da letra cursiva para a letra de forma. 
Figura 5 - O ensino da letra j de Jäger

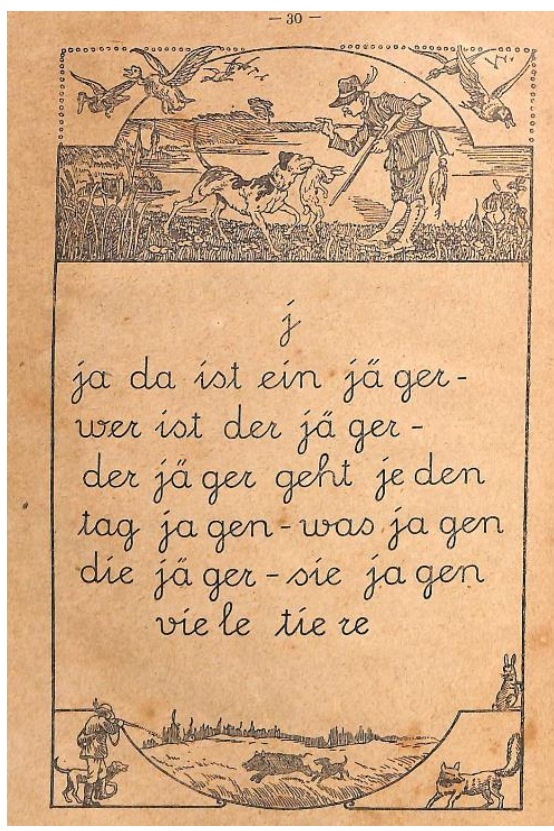

Fonte: Fibel, p. 30.
Figura 6 - Repetição da figura do Jäger

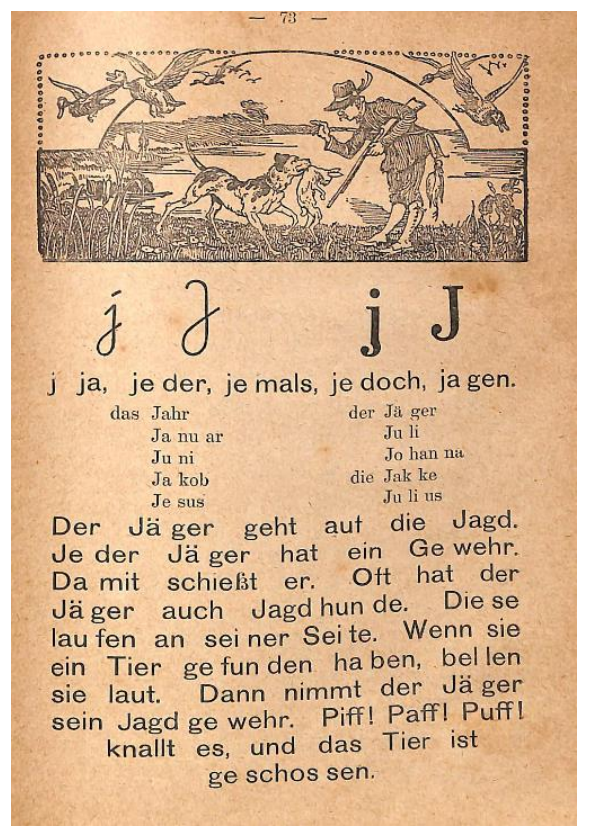

Fonte: Fibel, p. 73 .

Contudo, Frade (2010) considera que não se deve estabelecer significados para tudo o que se vê em manuais escolares e fazer suposições por conta de alguns indícios. Com isso não se pode afirmar que a repetição das gravuras era um recurso intencional do autor/editor enquanto exercício de memória ilustrativa. Considerando, também que a repetição de gravuras pode se tratar ainda da falta de recursos ilustrativos, ou algum outro método que requer uma análise seriada. Porém a hipótese de se tratar de um exercício de memória se justifica pelo fato que a repetição de gravuras ocorrer sempre relacionada ao ensino de uma mesma letra, como é o caso exemplificado nas figuras (5 e 6), em que ambas as páginas estão relacionadas a aprendizagem da letra $\mathrm{J}$ de Jäger (caçador). Além disso observou-se que ao contrário do que acontece na atualidade onde usa-se letras soltas (de fôrma ou script) no início da alfabetização, na Fibel acontecia o inverso ${ }^{18}$, primeiro a crianças era alfabetizada

\footnotetext{
${ }^{18}$ Segundo Brito (2002), a presença da letra cursiva e caligráfica nos munais escolares do início do século XX, se deve ao fato que nesse período a criança ser alfabetizada primeiro na letra cursiva. Porém o ensino da escrita manual no Brasil passou por alterações representativas com o passar dos anos, entre elas, a letra adota para a alfabetização sofreu uma inversão, da letra
} 
na letra cursiva, para depois ser apresentada à outras formas de escrita.

Quanto aos recursos didáticos visuais presentes na Schreiblesefibel für Unterricht der Elementarklassen, produzida pela editora Concórdia, ligada ao sínodo de Missouri, observamos que assim com a Fibel, este manual também faz uso de recursos visuais como suporte para alfabetização étnico-cultural dos alunos. Assim, apresenta características peculiares da cultura germânica, como a utilização da letra gótica' ${ }^{19}$ alemã, de estilo angulosa e com linhas quebradas e curvas que foi uma caligrafia típica usada em países alemães até o século XX. Trata-se assim de uma herança cultural trazida pelos alemães e seu uso propagado pelas editoras sinodais (ALBRECHT, 2019).

A Schreiblesefibel trabalha sequencialmente o ensino do alfabeto, separação de sílaba, encontros vocálicos e consonantais, e formação de palavras e frases e, por fim, pequenos textos. O que a diferencia da Fibel é a forma de expor o conteúdo, e também o uso das ilustrações como recurso didático visual, pois apresenta ilustrações unitárias, centralizada na página ao início de cada texto ou de cada letra a ser trabalhada. Outra peculiaridade é a representações de linhas caligráficas abaixo e ao lado da figura, através da qual é ensinada a escrita da letra de forma cursiva.

Conforme mostra a figura 7, a Schreiblesefibel apresenta a ilustração de objetos que de algum modo estavam presentes no cotidiano das crianças que viviam no meio rural, público-alvo destas cartilhas. São objetos de uso doméstico, ferramentas de trabalho agrícola, representações da fauna e da flora, e materiais de lazer, como os livros e instrumentos musicais, lembrando que a leitura e a musicalidade eram bastante estimulados nas escolas sinodais luteranas ${ }^{20}$.

cursiva passou a se usar a letra de forma.

19 A letra gótica foi um estilo de escrita caligráfica que surgiu na Europa, a partir do século XI na baixa Idade Média. Foi inspirada nas formas dos arcos ogivais amplamente utilizados nas catedrais góticas do período. Para saber mais sobre ver Bellard. Tipos e letras. Plataforma eletrônica. Brasil. Online. Disponível em: <http://www.tiposeletras.com.br/tag/letra-gotica/>. Acessado 21 ago. 2020.

${ }^{20}$ Para saber mais sobre ver: Weiduschadt (2007; 2012), Albrecht (2019). 
Figura 7 - Caligrafia e Imagens.

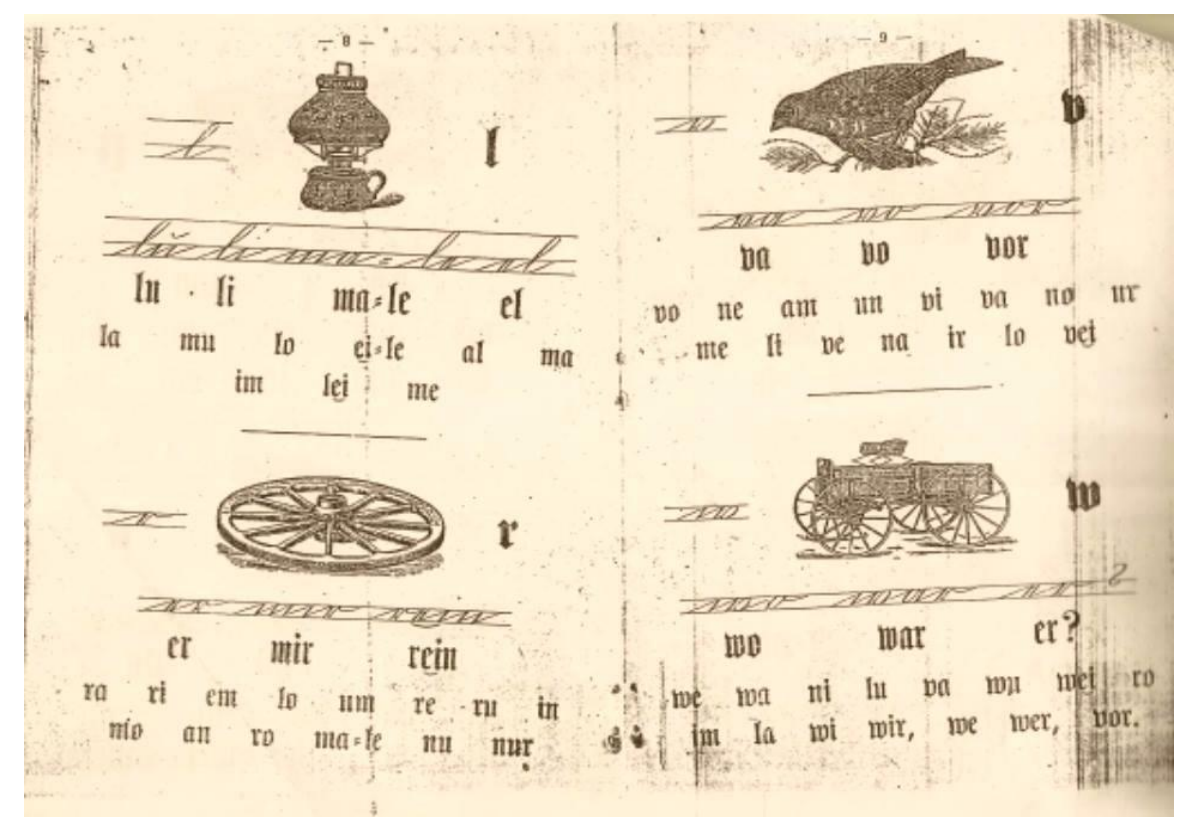

Fonte: Schreiblesefibel, p. 8 e 9 .

Ao analisar a figura 7 , identificamos atividades de ensino do alfabeto, na qual cada letra é representada por uma única imagem, nesse caso o ensino da letra L, R, V e W. Conforme pode ser visualizado no quadro que segue:

Quadro 4 - transcrição das imagens da figura 7 para grafia alemã, e portuguesa.

\begin{tabular}{|c|l|c|l|}
\hline $\begin{array}{c}\text { LETRA } \\
\text { ENSINADA }\end{array}$ & $\begin{array}{c}\text { ORTOGRAFIA } \\
\text { ALEMÃ }\end{array}$ & & $\begin{array}{c}\text { ORTOGRAFIA } \\
\text { PORTUGUESA }\end{array}$ \\
\hline L & Laterne & $=$ & Lampião \\
\hline $\mathrm{R}$ & Rad & $=$ & Roda \\
\hline $\mathrm{V}$ & Vogel & $=$ & Pássaro \\
\hline $\mathrm{W}$ & Wagen & $=$ & Carroça \\
\hline
\end{tabular}

Fonte: Quadro elaborado pelos autores com base nas observações das imagens da figura 7.

Com a descrição das imagens presentes na figura 7 , percebemos que o ensino de cada letra do alfabeto estava visualmente relacionado a uma única ilustração. Nesse sentido, Belmiro (2008), fazendo referência a Le Men, autora francesa, afirma que a imagem está lá, sobretudo, porque agrada às crianças, e 
porque ela serve a uma pedagogia do jogo que quer distrair a criança antes de fazê-la raciocinar. Nessa conjuntura o foco da Schreiblessfibel está voltado para o uso da ilustração como apoio pedagógico.

Observar-se também na figura 7 a influência da pedagogia norteamericana, uma vez que as cartilhas produzidas na editora Concórdia do Brasil integravam o modelo de iniciação a leitura do distrito luterano norte-americano, da editora Concordia Publishing House. O que se pode perceber conforme estudos de Albrecht (2019), no qual se apurou que as cartilhas passavam por uma adaptação a realidade brasileira, para atender escolas evangélicas luteranas do Brasil, porém mantinham a base estrutural americana. Apesar da diferenciação frente a cartilha concorrente, as contribuições da pedagogia norte-americana influenciaram não somente as cartilhas da editora Concórdia, mas foram disseminadas por outras produções didáticas no Brasil, principalmente no início do século XX, conforme mostram os estudos de Mortatti (2000), mas também em décadas posteriores, como indicam os estudos de Peres (2014).

Quanto a parte escrita, trata nesse primeiro momento de letras e sílabas soltas, porém o diferencial é que conforme o grau de aprendizagem ela sofre o acréscimo de frases e texto, acompanhados de suportes visuais indicando, que auxiliam a oralização das palavras. Conforme pode ser observado nas Figuras 8 e 9, onde terá um maior aprofundamento sobre o uso desses recursos na cartilha.

Ao folhear a Schreiblessfibel podemos constatar que a mesma apresenta uma progressão alfabética, na medida que a criança vai aprendendo as letras ocorre a incorporação de novos elementos textuais, como o ensino de encontros vocálicos e consonantais, além de junção silábica e a formação de palavras, pequenas frases e pontuação. Apresentando, portanto, em um mesmo texto várias regras de escrita.

Contudo, o emprego da imagem não é alterado, continua seguindo um padrão unitário, centralizado no começo de cada temática de ensino, como se fosse uma espécie de título da lição. No caso da figura 8, trata-se da representação de uma coruja, Eule em alemão, e de um livro, que significa Buch na língua alemã. 
Essa estrutura tipográfica de organização do conteúdo se repete ao longo da cartilha, sendo interessante destacar que em nenhum momento a imagem representada aparece na forma escrita, ou seja, a imagem está relacionada com a letra ensinada, com o encontro vogal ou consonantal em destaque, mas não aparece escrita no corpo do texto. $\mathrm{O}$ que exemplificado na tradução para o português das palavras que estão sendo ensinadas em alemão, no primeiro texto da página dezoito da Schreiblessfibel (Figura, 8).

Figura 8 - da ilustração ao traço.

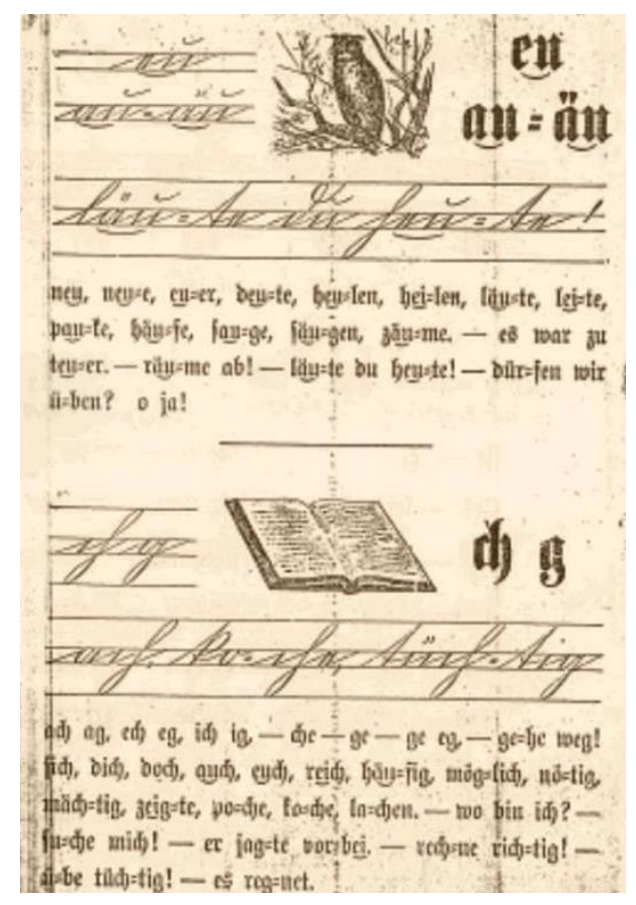

Fonte: Schreiblessfibel, p. 18. 
Quadro 5 - Tradução do texto 1 da página dezoito da Schreiblessfibel (Figura, 8).

\begin{tabular}{|l|l|}
\hline \multicolumn{1}{|c|}{ ORTOGRAFIA ALEMÃ } & \multicolumn{1}{c|}{ ORTOGRAFIA PORTUGUESA } \\
\hline neu & novo \\
\hline neu-e & novos, novas \\
\hline eu-er & vossos, vossas \\
\hline deu-te & aponta, indica \\
\hline heu-len & chora, urra \\
\hline läu-te & soa, repica \\
\hline lei-te & Liderar \\
\hline pau-ke & estuda (muito) \\
\hline Häu-se & casas \\
\hline sau-ge & suga \\
\hline säu-gen & mamar, amamentar \\
\hline zäu-me? & arrea (o cavalo) \\
\hline es war zu teu-er. & isso era muito caro. \\
\hline räu-me ab! & arrumar (a messa) \\
\hline läu-te du heu-te! & toca você hoje! \\
\hline dür-fen mir ü-ben? Oja! & Podemos treinar, exercitar? ah sim! \\
\hline
\end{tabular}

Fonte: Quadro elaborado pelos autores com base nas observações do texto 1 da página 18.

Estas palavras em alemão estão com consonância com as palavras Eule (coruja) e Buch (livro), que aparecem apenas ilustradas. Esse fato indica a relação estreita da oralidade e da escrita no processo de ensino aprendizagem. Nesse sentido, Bittencourt (2008), entende que as ilustrações nas cartilhas escolares do século XIX e XX “[...] criavam uma maneira especial de leitura, sobretudo na fase inicial da alfabetização, onde se mesclavam com a oralidade, suscitando comentários que deslizavam continuamente do escrito para o oral e do oral para o escrito" (p. 197).

Outro aspecto que pode ser observado é que ao lado da ilustração é apresentada a letra a ser ensinada, acompanhada de um texto em letra cursiva, entre linhas que indicam a adequada caligrafia (conforme é possível observar na figura 8). Esse é um aspecto cultural, que está vinculado ao modo pelo qual se compreende a importância da escrita bem elaborada. Kreutz (1994, p. 54), aborda a importância dada a caligrafia nas escolas do Sínodo de Missouri, quando observa que sem a facilidade dos recursos mecânicos, o apelo era para escrita manual, que deveria ser bem apresentada. Dedicava-se tempo e atenção para a 
caligrafia. O saber escrever de forma bonita era considerado um grande valor. Assim, consideramos que o escrever bem era parte do processo de alfabetização étnico-cultural proposto por estas obras didáticas, e a representação das linhas caligráficas devidamente preenchidas, enquanto modelo, comprovam o peso cultural do uso desse recurso em sala de aula.

Conforme Chartier (1990), quando se objetiva entender os usos culturais de determinados documentos é importante observar "os dispositivos tipográficos [...] e os papeis desempenhados pela imagem que dão a ler e a ver o texto" (p. 224). Uma vez que, o treino da caligrafia compunha o currículo escolar e saber escrever de forma correta, uniforme, legível e bem apresentada era algo bastante valorizado em uma sociedade étnica-religiosa luterana (ALBRECHT, 2019)

A Schreiblesefibel traz ainda vários recursos visuais, conforme pode ser observado na figura 9, que servem como dispositivos para auxiliar no processo de ensino aprendizagem. Entre esses recursos estão o sinal de dois traços paralelos entre sílabas (=), usado para indicar a união das sílabas e formar a palavra. Ainda, para o encontro vocálico é marcado com um traço curvo $(\smile$ ) abaixo das letras, identificando a ligação das vogais. A separação de frases é marcada pelo sinal do hífen (-). Para em um segundo momento incorporar a pontuação nos textos (. , ! ?). Assim, é possível observar que esses elementos eram pensados para auxiliar o trabalho do professor, ao mesmo tempo em que direcionavam e estimulavam a aprendizagem da criança a partir de recursos visuais. 
Figura 9- dispositivos ${ }^{21}$ para auxiliar na aprendizagem.
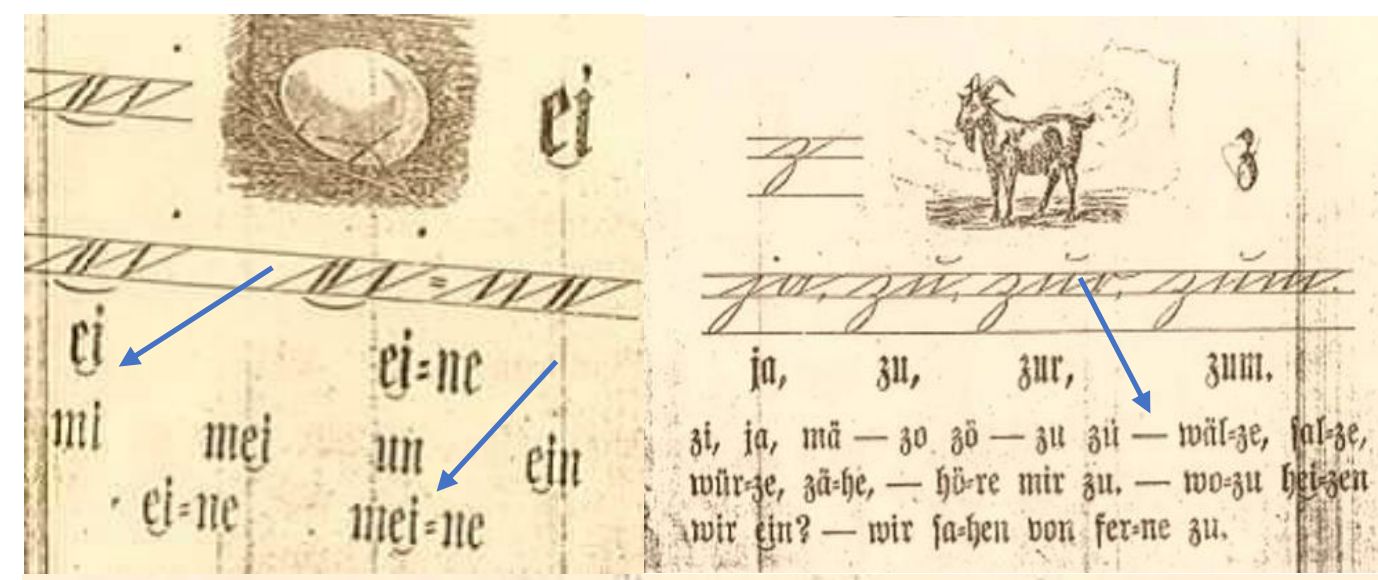

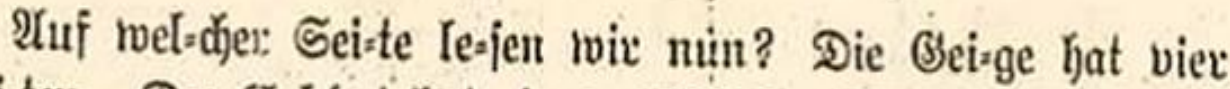
Saisten. Der Gö́s bat hat eimen Sä:bel. Die Gei=de ift jein.

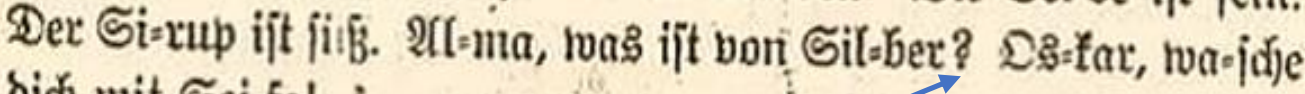
bid) mit Seizfe!

Fonte: Montagem com recortes das páginas 6, 13 e 24 da Schereiblesefibel.

Consideramos assim, que a cartilha Schereiblesefibel apresenta vários dispositivos de leitura que são incorporados no texto como recursos visuais auxiliares do processo de ensino e aprendizagem da leitura e da escrita da língua alemã, assim como, contempla recursos que intencionam a alfabetização étnicocultural. O mesmo pode ser observado em relação a cartilha Fibel, porém esta utiliza-se de outros recursos, havendo a ampla representação ilustrativa de espaços rurais e de ambientes de convivência nas comunidades rurais teutobrasileiras.

\footnotetext{
${ }^{21}$ As flechas foram postas nas imagens pelos autores para destacar a presença dos dispositivos utilizados como recursos auxiliares no processo de ensino e aprendizagem.
} 


\section{CONSIDERAÇÕES FINAIS}

A análise das cartilhas em paralelo com o contexto sócio, histórico e cultural das comunidades teuto-brasileiras, permite considerar que esses materiais didáticos respondiam ao que era considerado de maior relevância para as comunidades alemãs e pomeranas naquele período: a cultura escrita e a manutenção das práticas culturais. Nesse sentido, essas cartilhas, em língua alemã, foram produzidas especificamente para as escolas sinodais, contemplando nos recursos didáticos características e peculiaridades da época, assim, o discurso pedagógico e o modo de apresentação e organização do conteúdo a ser ensinado refletem a influência da cultura teuto-brasileira, inserida no contexto rural do Rio Grande do Sul, nas primeiras décadas do século XX. O que é perceptível na análise textual e visual dos livros analisados, com a integração dos temas ilustrados ao contexto de vivência diária das crianças, principalmente no que tange a relação com a igreja, o trabalho e o lazer das comunidades teutas, que simbolizam o contexto histórico e social inserido e a relação educacional adequada ao público afim (ALBRECHT, 2019).

A proposta de ensino tendo como recurso didático a representação imagética é mais explorada na cartilha Fibel fuer deutsche Schulen in Brasilien, na qual a ilustração atua como elemento determinador para a compreensão do texto. Além da interação texto-imagem, há um texto visual a ser lido em paralelo ao texto escrito. É possível considerar também que a ilustração é uma extensão do texto escrito, ou mesmo que, ilustração e texto se complementam. Havendo, portanto, a intenção de reproduzir situações ilustrativas nas quais o público-alvo estaria inserido, fazendo com que houvesse uma aproximação do texto com o leitor visado, a partir de signos do sistema sociocultural das comunidades germânicas.

Já na cartilha Schereiblesefibel für Unterricht der Elementarklassen, as ilustrações são unitárias e esteticamente mais simples, porém, podem ser facilmente reconhecidas e resinificadas pelas crianças, por remeter a objetos de 
uso cotidiano das comunidades. A Schereiblessfibel se destaca, ainda, pela exploração de recursos gráficos que dão suporte ao processo de ensino e aprendizagem e pela caligrafia gótica que predomina em toda a cartilha. A importância dada a "boa escrita" refletida por intermédio da reprodução de linhas caligráficas ao longo da cartilha, evidencia os aspectos culturais valorizados pelo grupo étnico para o qual a obra didática era direcionada.

Em ambas as cartilhas o contexto rural e cultural faz-se notar através de diferentes recursos visuais e textuais, tendo por objetivo o ensino da leitura e da escrita em língua alemã, assim como, a alfabetização étnico-cultural, enquanto exercício de valorização e manutenção de práticas culturais vivenciadas nas comunidades onde as escolas sinodais estavam inseridas. Deste modo, procuramos evidenciar, a partir de uma fonte de pesquisa específica - os livros escolares -, a circularidade das relações que faziam da escola uma das instituições fundantes para a constituição e manutenção indenitária das comunidades teutobrasileiras.

\section{REFERÊNCIAS}

ALBRECHT, Elias Kruger: Cartilhas em língua alemã produzidas pelos Sínodos Luteranos no Rio Grande do Sul: usos e memórias (1923-1945). 2019. 224 f. Dissertação (Mestrado em Educação) - Programa de Pós-Graduação em Educação, Faculdade de Educação, Universidade Federal de Pelotas, Pelotas, 2019.

ARENDT, Isabel Cristina. Representações da Germanidade: escola e professores no Allgemeine Lehrerzeitung für Rio Grande do Sul. 2005. Tese (Doutorado em História). Universidade do Vale do Rio dos Sinos/UNISINOS, São Leopoldo/RS, 2005.

BACELLAR, Carlos. Fontes documentais: uso e mau uso dos arquivos. In: PÍNSKY, Carla Bassanezí. Fontes históricas, 2.ed. São Paulo: Contexto, 2008, p. $23-80$.

BELMIRO, Celia Abicalil. Um estudo sobre relações entre imagens e 
textos verbais em cartilhas de alfabetização e livros de literatura infantil. 2008. 285 f. Tese (Doutorado em Educação). Universidade Federal Fluminense/UFF, Niterói/RJ: 2008.

BELLARD, Emmanuel. Tipos e letras: um site sobre tipografia. Letra gótica, 2016. Disponível online em: <http://www.tiposeletras.com.br/tag/letragotica/> Acesso em: 21 ago. 2020.

BITTENCOURT, Circe Maria Fernandes. Livro didático e saber escolar (1810-1910). Belo Horizonte: Autêntica, 2008.

BRITO, Aline Araujo. Reflexões acerca do ensino da letra cursiva em uma escola pública de Porto Alegre. 2008. Especialização (Alfabetização e Letramento nos Anos Iniciais da Escolarização). Universidade Federal do Rio Grande do Sul/UFRGS, Porto Alegre/RS, 2008.

CARDOSO, Rafael. O Início do Design de Livros no Brasil. In: CARDOSO, Rafael. O design brasileiro, antes do design: Aspecto da história gráfica, 1870-1960. São Paulo: Cosacnaify, 2005, p. 160-197.

CHARTIER, Roger. A História Cultural: entre práticas e representações. 2.ed. Rio de Janeiro: Bertand, 1990.

CHARTIER, Roger. A Aventura do Livro: do leitor ao navegador conversações com Jean Lebrun. São Paulo: UNESP, 1999.

CHARTIER, Roger. Do Livro à Leitura. In: CHARTIER, Roger. Práticas da Leitura. 2. ed. São Paulo: Estação Liberdade, 2001, p. 77-105.

CHOPPIN, Alain. O historiador e o livro escolar. História da Educação, ASPHE/FaE/UFPel, Pelotas, n. 11, p. 5 -24, abril, 2002.

DREHER, Martin Norberto. Igreja e Germanidade: estudo crítico da história da Igreja Evangélica de Confissão Luterana no Brasil. Porto Alegre: EST, 1984.

DREHER, Martin Norberto. Wilhelm Rotermund: seu tempo - suas obras. 2. ed. São Leopoldo: Oikos, 2014.

FARIA, Ana Lúcia Goulart de. Ideologia no livro didático. 2.ed. São Paulo: Cortez, 1984.

FONSECA, Maria Ângela Peter da. Deutsche Schulen urbanas no Pampa ou o Pampa dentro de Deutsche Schulen? Cultura Escolar Conforme: Collegio Allemão de Pelotas e Collegio Rio Grandense do Rio Grande (19121936). 2017. 269 f. Tese (Doutorado em Educação) - Universidade Federal de 
Pelotas/UFPel, Pelotas/RS, 2017.

FRADE, Isabel Cristina Alves da Silva. Livros para ensinar a ler e escrever: uma pequena análise da visualidade de livros produzidos no Brasil, em Portugal e na França, entre os séculos XIX e XX. In: BRAGANÇA, Aníbal; ABREU, Márcia (Orgs.). Impresso no Brasil: Dois séculos de livros brasileiros. São Paulo: Editora UNESP, 2010, p. 171-190.

FRADE, Isabel Cristina Alves da Silva. Cartilha Analytica publicada por Francisco Alves: aspectos da materialidade entre ordenamentos pedagógicos e editoriais. In: I SEMINÁRIO BRASILEIRO SOBRE LIVRO E HISTÓRIA EDITORIAL, $1^{\text {a }}$, 2004, Rio de Janeiro/RJ. Anais... Rio de Janeiro: FCRB, 2004, p. 1- 17. Disponível online em

$<$ www.livroehistoriaeditorial.pro.br/pdf/isabelcristina.pdf $>$. Acesso em: 20 jan. 2020

GALVÃO, Ana Maria de Oliveira; BATISTA, Antônio Augusto Gomes. O estudo dos manuais escolares e a pesquisa em história. In: BATISTA, Antônio Augusto Gomes; GALVÃO, Ana Maria de Oliveira. Livros Escolares de Leitura no Brasil: elementos para uma história. Campinas: Mercado das Letras, 2009, p. 11-40.

HOFF, Sandino; CARDOSO, Maria Angélica. Realismo pedagógico. Revista HISTEDBR, $\mathrm{s} / \mathrm{n}, \mathrm{v} .20, \mathrm{~s} / \mathrm{p}, 2006$. Disponível online em: $<$ http://www.histedbr.fe.unicamp.br>. Acesso em: 26 ago. 2020.

JOLY, Martine. Introdução à análise da imagem. 11. ed. Campinas: Papirus, 2006.

KREUTZ, Lúcio. Material didático e currículo na escola teutobrasileira do Rio Grande do Sul. São Leopoldo: Unisinos, 1994.

KREUTZ, Lúcio. A Representação de Identidade nacional em escolas da imigração alemã no Rio Grande do Sul. Revista História da Educação. v. 3 , n. 5, p.141-164 jan./jul. 1999. Disponível online em: https://seer.ufrgs.br/asphe/issue/view/1291/showToc. Acesso em: 07 de jan. de 2021.

LE GOFF, Jacques. História e Memória. 4.ed. Campinas: Editora da Unicamp, 1996.

MOCELLIM, Alan Delazeri. A comunidade: da sociologia clássica à sociologia contemporânea. PLURAL, São Paulo, v. 17, n. 2, p. 105-125, 2011. Disponível online em: <www.periodicos.usp.br/plural/article/download/74542/78151>. 
Acesso em: 13 ago. 2020.

MORTATTI, Maria do Rosário Longo. Cartilha de alfabetização e cultura escolar: Um pacto secular. Cadernos Cedes, ano XX, n. 52, p,41-54, nov. 2000. Disponível online em: <www.scielo.br/pdf/ccedes/v20n52/a04v2052>. Acesso em: 23 ago. 2020.

PERES, Eliane. T. Influências do Pensamento Norte-Americano na Produção de Cartilhas para o Ensino da Leitura e da Escrita no Rio Grande do Sul na Década de 1960. In: Maria do Rosário Longo Mortatti; Isabel Cristina Aves da Silva Frade. (Org.). História do Ensino de Leitura e Escrita: Métodos e Material Didático. 1ed.Marília: Editora da UNESP/Oficina Universitária, 2014, v. 1, p. 93-120.

PESAVENTO, Sandra Jatahy. História e História Cultural. 2. ed. Belo Horizonte: Autêntica, 2005.

SCHAFFER, Schirlei Conceição Barth. Descrição Fonética e Fonológica do Pomerano falado no Espírito Santo. 2012. 130 f. Dissertação (Mestrado em Estudos Linguísticos). Universidade Federal do Espírito Santo/UFES, Vitória/ES, 2012.

THUM, Carmo. Educação, história e memória: Silêncio e reinvenções pomeranas na serra dos tapes. 2009. 334 f. Tese (Doutorado em Educação) Universidade do Vale do Rio dos Sinos/UNISINOS, São Leopoldo/RS, 2009.

VALDEMARIN, Vera Teresa. Lições de coisas: Concepção científica e projeto modernizador para a sociedade. Cadernos Cedes, ano XX, n 52, p. 74 - 87, novembro, 2000. Disponível online em:

<http://www.scielo.br/pdf/ccedes/v20n52/ao6v2052.pdf>. Acesso em: 29 jul. 2020.

VALDEMARIN, Vera Teresa. História dos métodos e materiais de ensino: a escola nova e seus modos de uso. São Paulo: Cortez, 2010.

WEIDUSCHADT, Patrícia. O Sínodo de Missouri e a educação pomerana em Pelotas e São Lourenço do Sul nas primeiras décadas do século XX: Identidade e cultura escolar. 2007. 256 f. Dissertação (Mestrado em Educação) - Universidade Federal de Pelotas/UFPel, Pelotas/RS, 2007.

WEIDUSCHADT, Patrícia. A revista "O Pequeno Luterano" e a formação educativa religiosa luterana no contexto pomerano em Pelotas - RS (1931 - 1966). 2012. 275 f. Tese (Doutorado em Educação) - Universidade do Vale do Rio dos Sinos/UNISINOS, São Leopoldo/RS, 2012. 
WEIDUSCHADT, Patrícia; TAMBARA, Elomar Antonio Callegaro. Cartilhas e livros didáticos nas escolas pomeranas luteranas no sul do rio grande do sul (1900-1940). Revista História da Educação, v. 20, n. 20, p. 275-296, set./dez. 2016. Disponível online em:

https://seer.ufrgs.br/asphe/issue/view/2684/showToc. Acesso em: o7 de jan. 2021

ELIAS KRUGER ALBRECHT possui Graduação em História Licenciatura pela Universidade Federal de Pelotas (2017) e Especialização em Metodologia de Ensino de História pelo Centro Universitário Leonardo Da Vinci (2020). Mestrado em História da Educação pelo Programa de PósGraduação em Educação (PPGE) da Universidade Federal de Pelotas (2019). Doutorando em História da Educação pelo Programa de Pós- Graduação em Educação (PPGE) da Universidade Federal de Pelotas. Membro do grupo de pesquisa: Centro De Estudos e Investigação em História da Educação (CEIHE).

E-mail: eliask.albrecht@gmail.com

(1) http://orcid.org/0000-0002-7381-8909

LISIANE SIAS MANKE possui Graduação em História (2002) e Especialização em História do Brasil (2003) pela Universidade Federal de Pelotas, Mestrado (2006) e Doutorado (2012) em Educação pelo PPGE da Faculdade de Educação da UFPel, como estágio de doutorado sanduíche (PDEE) na École Normale Superièure de Lyon/França. Realizou estágio de pósdoutorado (com bolsa CNPQ) na Universidade Federal de Minas Gerais em 2015-2016. É Professora do departamento de História da Universidade Federal de Pelotas, atuando na área de Ensino de História, e no Programa de Pós-graduação em História.

E-mail: lisianemanke@yahoo.com.br

(1) http://orcid.org/0000-0001-5085-8791

Recebido em: 02 de setembro de 2020

Aprovado em: 04 de janeiro de 2021

Editora responsável: Terciane Luchese 
Associação Sul-Rio-Grandense de Pesquisadores em História da Educação - Asphe

Artigo de acesso aberto distribuído nos termos de licença Creative Commons. 